\title{
Materialism as the Mediator of the Association between Subjective Well-being and Impulsive Buying Tendency
}

\author{
Beata Seinauskiene, Jurate Mascinskiene, Indre Petrike, Ausra Rutelione
}

Kaunas University of Technology

K. Donelaicio st. 73, 44029, Kaunas, Lithuania

E-mail.Beata.seinauskiene@ktu.lt,jurate.mascinskiene@ktu.lt,indre.jucaityte@ktu.lt,ausra.rutelione@ktu.lt

cross $^{\text {ref }}$ http://dx.doi.org/10.5755/j01.ee.27.5.13830

The findings of the research are consistent and demonstrate the negative relationship between materialism and subjective well-being. The literature also suggests that materialism is one of the main predictors of impulsive buying. It should also be noted that though the relationship of materialism and subjective well-being has been extensively explored, the ambiguity with respect to the directionality of the relationship still prevails in the literature. Subjective well-being recently became the subject of interest of scientists from different fields. However, the relationship of well-being with consumer buying behaviour received scarce attention. In particular the effect of life satisfaction (well-being) on consumers' tendency toward impulsive buying behaviour, except for a few attempts, has been nearly left unaddressed. This study attempts to explain the underlying mechanism of the relationship of subjective well-being and inclination toward impulsive buying behaviour. We hypothesise that subjective well-being affects the propensity toward impulsive buying indirectly through the presence of materialism. Lower levels of well-being increase materialism that in turn leads to a higher-level impulsive buying tendency. The results of the applied path analysis (regression based mediation) support the assumption of the indirect well-being-impulsive buying tendency link, mediated by the level of materialism.

Keywords: Materialism, Subjective Well-Being, Impulsive Buying Tendency, Impulsive Buying, Mediation.

\section{Introduction}

The topic of materialism has caused great interest among marketing researchers who have disclosed this phenomenon's links with various social and psychological maladies (Ruvio et al., 2014). Materialism reflects the values prevalent in today's society, which have a detrimental impact on both personal and collective well-being (Burroughs et al., 2013; Burroughs and Rindfleisch, 2012). Empirical findings confirming the negative effects of materialism are consistent and demonstrate that the higher priority people assign to values and goals related to money and possession compared with other life goals, the lower is their satisfaction with life and the poorer self-realization: such people are less happy (Podoshen et al., 2014), less viable, more prone to depression, experience more anxiety, behavioural disorders, and other forms of psychopathology (Shrum et al., 2014; Dittmar et al., 2014). Materialistic values are associated with antisocial and egocentric consumer decisions and treating people as means of achieving further materialistic ends (Kasser \& Ryan, 1993; Kasser, 2002). Materialism, expressed as a permanent consumer concern for possession and faith in the ability of possessions to make life better, can become an obstacle to sustainable production and consumption patterns (Scott et al., 2014). The consumer culture related to materialism encourages indifference to environmental concerns (Good, 2007; Kasser \& Sheldon, 2000). Members of the public prone to increasing consumption are characterized by inferior personal budget management skills (Lemrova et al., 2014) and are inclined to excessive consumption and uncontrolled, compulsive buying (Garðarsdottir \& Dittmar,
2012). Materialistic values determine risky consumer behaviour and financial debt (Richins, 2011). Meanwhile, the subjective well-being, as an antecedent and the consequence of materialism, is associated with more desirable individual's behaviour in society, and in economically developed countries it is becoming an important policy issue of welfare economics (Dittmar et al., 2014). The negative effect of materialism on personal and collective well-being grounds the necessity for further research on the causes and consequences of materialism. To elevate knowledge of the phenomenon of materialism, the researchers (Shrum et al., 2014; Burroughs \& Rindfleisch, 2012) encourage the continuation of these studies looking at materialism from different theoretical perspectives while addressing potentially new antecedents. Researchers are invited to carry out studies explaining the underlying mechanism and boundary conditions of the relationships (Ruvio et al., 2014; Shrum et al., 2014; Burroughs \& Rindfleisch, 2012).

The high abundance of different types of studies (conducted in different age groups and different cultural contexts) provides unambiguous findings and allow to conclude that a negative link between materialism and subjective well-being exists (Kasser et al., 2014; Dittmar et $a l ., 2014)$. Nevertheless, scientists note that the question of the direction of causality still remains unanswered. Researchers' attention in the field of consumer behaviour is directed to the consequences of materialism, namely to the detrimental and addiction linked impulsive and compulsive buying behaviour. However, there is a lack of research combining the above concepts into a model that is integrated and explains the interconnectedness, therefore, 
revealing the nature of the subjective well-being and impulsive buying relationship and the role materialism plays in this connection. Otero-Lopez et al. (2011) research, which can be found among the few hypothesising causal links, determined that life satisfaction partially mediates the connection between materialism and addictive buying. Although these authors hypothesised that materialism is an antecedent of life satisfaction, they noted that bidirectional dependencies between these constructs are also possible. Extending the previous studies, Tsang et al. (2014) found that relationship between materialism and life satisfaction is mediated in sequence by gratitude and basic psychological need satisfaction. Noting that explanatory processes (mediation), underlying the relationship between materialism and subjective wellbeing, received insufficient attention from researchers, Unanue et al. (2014) hypothesised and explored the mediational role of fundamental psychological needs satisfaction and frustration in explaining the relationship between materialism and subjective well-being. The authors also pointed out that one cannot deny the possibility of an alternative that reduced well-being can induce orientation to materialistic values. In the light of the impetus to continue research on this topic, this article aims to ground conceptually and to test empirically the links between materialism, subjective well-being, and impulsive buying tendency. Contribution to the materialism literature unfolds through the theoretical reasoning and empirical testing of the premise that materialism functions as a mechanism through which subjective well-being is linked with impulsive buying.

Materialism is more likely a result of education, and not naturally inherent in individuals (Burroughs \& Rindfleisch, 2012). Therefore, the awareness of factors, that evoke and suppress materialism and its consequences, would enable the development of corresponding strategies for materialism reduction and would provide implications on how to mitigate negative consumer behaviour, manifested as uncontrollable compulsive buying, excess expenditure as well as overconsumption stemming from materialism.

\section{Conceptualization of Materialism}

Materialism is defined through various theoretical perspectives. Two approaches to materialism are widely acknowledged within consumer behaviour field: one is based on personality traits (Belk, 1985), and the other builds materialism concept on the personal values, revealing what place material acquisition and possession occupies in the life of the consumer (Richins \& Dawson, 1992).

Belk (1985) conceptualizes materialism as the undesirable personality traits related to material possession, such as possessiveness, non-generosity, and envy. The dimension of possessiveness is defined as a personal inclination to keep possession control and ownership. Non-generosity is conceptualised as the unwillingness to give the possession or share it with others. Envy is defined as the desire for others' possession, a propensity to become indignant at those who have the desired possession, or the tendency to feel personally humbled when the desired possession holder is perceived as unworthy of this property (Belk, 1985).

Richins and Dawson (1992) conceptualize materialism as personality values that show the importance the consumer assigns to possession or acquisition as necessary or preferred behaviour in order to reach the desired state. Proponents of this view assert that it is values that determine people's choices and behaviour in various situations, including consumption. Personal values based conceptualisation of materialism includes three interrelated aspects: the belief that both personal success and that of others is judged by possession (success dimension); the fundamental attitude that material possession and wealth occupy a central place in a person's life (centrality dimension); and the view that possessions and their acquisition increase happiness and satisfaction with life (happiness dimension) (Richins \& Dawson, 1992; Richins, 2004). The consumer value-based conceptualization of materialism encompassing the dimensions of the centrality, success, and happiness is widespread in consumer behaviour studies. This view holds that the more consumers value material reward as an essential purpose in their life, see material possessions or their acquisition as a key way towards success and happiness, and use material possession to define their identity, the higher they are considered to be materialists.

Research work shows that materialism comes more from upbringing than inherently (Burroughs \& Rindfleisch, 2012). Materialistic values are formed at an early age and remain relatively stable throughout a consumer's lifetime (Burroughs \& Rindfleisch, 2002). These values are regarded as an adaptive behavioural response to the developmental, economic, social, or existential insecurities (Burroughs \& Rindfleisch, 2012). Although the two theoretical approaches to materialism differ, the key point, common to both explanations, is that materialism is considered harmful to an individual and is linked to negative consumer behaviour (Segev et al., 2015).

Two streams of research have shed light on materialism phenomenon: studies analysing the association between materialism and subjective well-being and research that is focused on the materialism and consumer behaviour relationship (Otero-Lopez et al., 2011). Within the field of consumer behaviour, materialism is considered an antecedent of consumer behaviour and, in this context, the main focus of researchers turns to such addictive buying forms as impulsive and compulsive buying (Dittmar, 2005; Podoshen \& Andrzejewski, 2012).

\section{Subjective Well-being as an Antecedent of Materialism}

Conceptualization of subjective well-being. According to Diener (1984), subjective well-being reflects how people feel and what they think about their lives, therefore, includes emotional and cognitive assessment of one's life. Emotional assessment is based on feelings - mood and emotions, while the cognitive assessment is known as life satisfaction (Diener, 1984; Diener \& Chan, 2011). Thus, the construct of subjective well-being consists of a few components: life satisfaction, positive affect or frequent experience of positive emotions (feeling of happiness), and 
a low level of negative affect or relative absence of unpleasant emotions (such as dejection) (Diener, 1984; 2000; Luhmann et al., 2012). Other authors employ synonymous concepts to describe a former phenomenon. One of these constructs, according to Luhmann et al. (2012) is the concept of happiness, used in scientific works to describe a particular pleasant state, such as happy.

The relationship between materialism and subjective well-being. The scientific literature is rich in studies showing that materialism and subjective well-being is negatively related (Kasser, Ahuvia, 2002; Burroughs, Rindfleisch, 2002). Kasser \& Ahuvia (2002) found that respondents who were characterised by strongly internalised materialistic values exhibited lower selfrealization and vitality, were less happy, felt increased anxiety and were suffering from physical complaints. Materialism is negatively associated with various aspects of life satisfaction, such as satisfaction with family, friends, income, and life as a whole (Richins \& Dawson, 1992). Roberts and Clement (2007) study showed that overall materialism and its happiness dimension was negatively associated with all eight quality of life facets (satisfaction with family, friends, self, residence, health, amount of fun, income, and job), while centrality and success dimensions were negatively correlated with, respectively, seven (excluding satisfaction with family and health) and six (excluding satisfaction with family, health, and labour) quality of life areas.

Although a great number of different types of research observe a negative relationship between materialism and subjective well-being (Kasser et al., 2014; Dittmar et al., 2014), scientists, nevertheless, note that these studies are accompanied by ambiguity concerning the causal direction of the connection between materialism and subjective wellbeing. According to Shrum et al. (2014), two alternative explanations for the correlational connection between aforementioned constructs are prevalent in the literature. Low subjective well-being leads to higher degree of materialism because less happy people are expecting to alleviate their negative feelings through greater consumption. The particular explanation considers materialism as a coping mechanism of the undesirable psychological state. Another alternative explanation focuses on the possible effect of other factors both on materialism and subjective well-being. The latter approach emphasises that conceptualization of materialism, while based on the relatively stable value orientation and personality traits, does not allow to determine reliably whether materialism in itself is a subjective well-beings' determinant, or is it affected by other factors that are related both to materialism, as well as to subjective wellbeing. In conclusion authors (Richins \& Dawson, 1992; Burroughs \& Rindfleisch, 2002; Shrum et al., 2014) assume that relationship between materialism and subjective well-being may be bidirectional.

As pointed out by Bauer et al. (2012), it is likely the case that materialism is a consequence of personal dysfunction, and not vice versa. Belk (1985) suggests that those who for various reasons have experienced dissatisfaction with life are expected to be inclined towards materialism because they think that owning things is the main source of happiness. Roberts and Clement (2007) also highlight that those dissatisfied with life, or at least with some aspect of it, are the individuals likely to employ material possession as an attempt to cope with these feelings, which is why the above-mentioned authors emphasise the need for research on the role of materialism as a coping strategy. Alluding to materialism as the consequence of subjective well-being can be found in the works of other authors. For instance, Kasser et al. (2004) state that materialism is considered to be a coping mechanism for people whose basic needs such as security, competence, self-esteem, or belonging to a group (social ties) have not been met. Segev et al. (2015) also assumed that materialism is a coping mechanism, and found that depression was positively associated with the overall materialism and happiness dimension. Lastovicka and Sirianni (2011) suggest that attachment to possession may develop as a strategy, compensating loneliness and a lack of social affiliation (domain of consumer well-being). The research results (Reeves et al., 2012) also reveal that consumers more predisposed towards materialism and compulsive buying lack of a clear sense of self-awareness and positive self-regard, which is why these consumers need an external stimulus as a possible escape from aversive consequences of introspection. Such consumers are trying to compensate for their deficiencies by turning to external sources of satisfaction, including materialistic aspirations (Reeves et al., 2012). Thus, it is hypothesised that:

$\mathrm{H} 1$ : Subjective well-being has a negative impact on materialism.

\section{Impulsive Buying as a Consequence of Materialism}

Conceptualization of impulsive buying. Impulsive buying is described as an extraordinary and exciting consumer experience, which is characterized by the "sudden, often powerful and persistent urge to buy something immediately" (Rook, 1987, 191 p.). Beatty \& Ferrell (1998, 170 p.) describe impulsive buying similarly arguing that it is "a sudden and immediate purchase with no pre-shopping intentions either to buy the specific product category or to fulfill a specific buying task." According to Sharma et al. (2010), the rapidity of impulsive buying in this hedonistically complex behaviour prevents any conscious considerations of the alternatives or future consequences. In addition, these authors note that impulsive buying is emotionally activated, unyielding cognitive control and manifests itself in irresistible purchase behaviour when faced with the attractive object. The inner conflict between the pleasure-seeking consumption and self-control to resist the impulse turns into increased impulsive buying when the desire to consume outweighs the will to resist (Zhang \& Shrum, 2009; Punj, 2011).

Some authors (Faber \& O'Guinn, 2008) classify impulsive and compulsive buying as qualitatively different concepts, although the similarity of the phenomena is evidenced in their similar consequences (Flight et al., 2012; Kwak et al., 2006) as well as the determinants of both behaviour share considerable overlap, for instance, level of materialism and identity issues (Verplanken \& Sato, 2011), low self-esteem and conceptual connection to stress (Ruvio et al., 2014; Sneath et al., 2009). Ultimately, 
deviation from buying behaviour considered as normal, greater emotional involvement in the buying process and the inability to resist the desire to buy is inherent in both the impulsive and compulsive buying (Roberts et al., 2015).

Otero-Lopez and Villardefrancos (2013) use a more inclusive concept of excessive buying, consisting of impulsive, compulsive and addictive buying. Ruvio et al. (2014) adopt the concept of maladaptive consumption behaviour when referring to compulsive and impulsive buying. Both impulsive and compulsive buying phenomena are considered as being less rational consumer behaviour (Roberts, Manolis \& Tanner, 2008).

Other authors (Thompson \& Prendergast, 2015; d'Astous, 1990; Clark \& Calleja, 2008; Ridgway et al., 2008) consider impulsive buying to be a less pronounced manifestation of compulsive buying where impulsive buying signifies the initial stage and compulsive buying denotes the other extreme of the same behavioural continuum. The latter conceptualization is based on the belief that impulsive buying gradually leads some consumers to compulsive buying, which is associated with addiction, manifesting in the habit of repeat buying, and characterized by a lack of control over buying behaviour. In this study, the authors relied on the latter conceptualization, when compulsive buying is described as an extreme form of impulsive buying, and both phenomena are primarily distinguished by the strength of the behavioural manifestation. Therefore, the two concepts are used interchangeably. Furthermore, impulsive buying is treated as relatively harmless consumer behaviour as long as it does not turn into compulsive buying (Verplanken \& Sato, 2011).

The relationship between materialism and impulsive buying. There is considerable evidence accumulated suggesting that materialistic values and desire for possessions are strongly positively correlated with impulsive buying (Xiao \& Nicholson, 2013; Podoshen \& Andrzejewski 2012; Sun \& Wu, 2011). The conceptualization of materialism reveals that the identity and self-esteem of individuals, whose endorsement of materialistic values is high, depend on the amount and nature of accumulated material wealth. For that reason, the acquisition of material wealth is considered for these individuals to be the main purpose of life and the way to achieve success, happiness, and identity (Richins, 1994, 2004). Therefore, it is very unlikely that such consumers will be able to resist the temptation to buy when faced with an attractive object that has the potential to raise their status or gain them the approval of their peers (Badgaiyan \& Verma, 2014). Dittmar and Bond (2010) found that it is the lack of identity felt by materialists that is related to their increased consumer impulsivity when faced with goods that express identity. The authors mentioned above describe the endorsement of materialistic values as identity construction through the symbolic potential of material goods and argue that consumer impulsiveness can be conceptualized as the behaviour of searching for an identity inherent in individuals predisposed to materialism. According to Belk (1985), it is likely that consumers distinguished by materialistic traits (namely non- generosity), will be more inclined to indulge in impulsive buying.

Empirical findings confirm that compulsive buying is also characterized by a higher degree of materialism (Yurchisin \& Johnson, 2004; O’Guinn \& Faber, 1989; Harnish \& Bridges 2015). Dittmar (2005) suggests that materialistic values direct the person to consumption, which is considered to be a kind of strategy to help deal with the perceived self-concept incompatibility. The authors found that the devotion to material needs and desires strongly and directly predicts a predisposition to compulsive buying behaviour among women of all ages and young men in the samples. The acknowledgment of the indirect positive relationship between materialism and impulsive buying is evident in other studies, too. In particular, Roberts and Pirog (2012) found that materialism is positively related to impulsivity, which in turn stimulates addictive consumption (dependency on mobile phones and instant messaging). Research suggests impulsive individuals are more likely to engage in impulsive buying (Xiao \& Nicholson, 2011). Materialism is negatively related to impulse control (Rose, 2007), the lack of which can lead to impulsive buying. Boujbel and d'Astous (2015) also found that materialism was negatively correlated with the ability of consumers to control their consumption desires.

In addition, the explanation of materialism and impulsive buying both are favouring the hedonistic conception. Researchers contend that impulsive buying is associated more with hedonic rather than utilitarian buying motives (Rook \& Hoch, 1985; Tifferet \& Herstein, 2012; Verplanken \& Sato, 2011; Sharma et al., 2010). The hedonic adaptation theory explains why materialistic consumers continue to buy and use items, never reaching the point when their lives would be considered as providing enough pleasure and satisfaction (Chancellor \& Lyubomirsky, 2011). This endless cycle of acquisition and adaptation is called hedonic treadmill (Brickman \& Campbell, 1971). Materialism inclined consumers gain a hedonic emotional elevation from the purchase, followed by a post-purchase gradual hedonic decline, stimulating materialistic consumers to continually want to acquire more and more goods to return the positive feelings experienced upon last purchase (Richins, 2013). Therefore, building on the studies that explore the relationship between materialism and impulsive buying, the following is hypothesised:

H2: Materialism has a positive impact on impulsive buying.

\section{Relationship between Subjective Well-being and Impulsive Buying}

Impulsive buying has been noted to function as a way, alleviating the unpleasant psychological states (Herabadi et al., 2009), for instance, helping to compensate the discrepancies between ideal and actual self-perception known as the perceived identity deficit (Dittmar, 2005). Impulsive buying can play an important role in the mood regulation process by being invoked at low mood moments as a reward and self-gift (Sneath et al., 2009) or reward for hard work (Darrat et al., 2016). For example, Verplanken 
et al. (2005) found that the impulse buying tendency is linked with sustained negative mood and low self-esteem. Similarly, Silvera et al. (2008) detected the connection between the impulse buying tendency and low self-esteem. The results of Rook and Gardner (1993) demonstrated that impulsive buyers were more likely to buy on impulse when feeling depressed and miserable. Likewise, compulsive buying occurs as a response to negative events and feelings, aiming to reduce anxiety and unhappiness (O’Guinn \& Faber, 1989).

While significant research on the relationship between feelings and buying addiction has been conducted providing empirical evidence to support the connection between different types of negative affect and addictive buying, researchers have relatively neglected the direct impact of subjective well-being or its separate aspects (such as life satisfaction) on impulsive or compulsive buying. Among those few research is that of Manolis and Roberts (2012), which had confirmed the assumption that compulsive buying is negatively and directly associated with subjective well-being. In addition, Silvera at al. (2008) found that the cognitive aspect of impulsive buying was positively associated with negative affect and was negatively associated with satisfaction with life. OteroLopez et al. (2011) study also demonstrated that dissatisfaction with life (one of the components of subjective well-being), being induced by materialistic aspirations for success and happiness, increases the risk of addictive buying.

Allusions to the fact that subjective well-being is related to excessive buying can be detected in the heart of the conceptualization of compulsive buying. One of the explanations of compulsive buying is based on the attitude that such behaviour serves as a mood manipulation tool for people exposed to negative feelings (Faber \& Christenson, 1996). Muller et al. (2011) found that people inclined to compulsive buying had more symptoms of depression and were characterized by a higher degree of materialistic value endorsement. The results of this research proved that materialism and depression jointly affect compulsive buying. In subsequent studies, Muller et al. (2014) found that only depression was significantly associated with compulsive buying and explained this relationship on the premise that compulsive buying is used to escape from the negative mood state. Other authors explained predisposition toward compulsive buying based on escape theory, too (Faber, 2006; Rodriguez-Villarino et al., 2006; Roberts et al., 2015). As pointed out by Faber (2006), for some people the inability to fulfill the excessive expectations they raised for themselves becomes extremely painful. When the feeling of failure, anxiety, and depression caused by this situation, become unbearable, people search for ways to block out this painful selfawareness. Based on escape theory, the immersion into compulsive buying is considered as one of the ways to avert the painful self-awareness. Similarly, Roberts et al. (2015) presuppose that adults use compulsive buying as a way to cope with a sense of inadequacy and gloomy future prospects. Rodriguez-Villarino et al. (2006) reported a link between buying addiction and the use of passive coping strategies. The empirical findings of those authors supported the escape theory assumptions, confirming that the propensity to avoid problems and unpleasant feelings creates conditions for the manifestation of compulsive buying, which temporarily relieves the discomfort. Similarly, Harnish and Bridges (2015) found that problem avoidance was a predictor of compulsive buying further supporting the notion that compulsive buying is an escape from the causes of anxiety and negative emotions experienced by compulsive buyers.

The stress-induced anxiety was found to be positively associated with compulsive buying behaviour (Darrat et al., 2016). Impulsive and compulsive buying are closely linked to mood-regulating consumption, marked by the therapeutic power arising from consumption activities (Luomala, 2002). Sneath et al. (2009), for instance, found that impulsive buying serves to individuals as a tool reducing depression caused by stressful incidents. To alleviate emotional suffering respondents actively engaged into mood elevating buying, which they perceived as a self-reward. The mentioned authors argue that individuals' propensity to self-gifting can be viewed as a response to disappointments and depression. In such cases, motivation to buy is not based on the pursuit of utility but is rather construed as a desire to manage emotional states. Sneath et al. (2009) contend that both impulsive and compulsive buying may be invoked to lift a depressed mood and to relieve the negative affect. Given the above, we hypothesise that subjective well-being is negatively associated with impulsive buying:

H3: Subjective well-being has a negative impact on impulsive buying.

\section{Relationships between Subjective Well-being, Materialism, and Impulsive Buying}

The theoretical justification of subjective well-being as the antecedent of materialism and impulsive buying as the consequence of materialism, as well as interpretation of materialism as a coping mechanism (Kasser et al., 2004, Segev et al., 2015, Lastovicka \& Sirianni, 2011, Reeves et al., 2012), which manifests itself as the strategy, compensating the unfulfilled needs or personal weaknesses, lead to the assumption that materialism potentially mediates the relationship between subjective well-being and impulsive buying tendency. The conceptualization of compulsive buying as a result of the high level of materialism and the outcome of low selfesteem (O'Guinn \& Faber, 1989) also suggests that materialism functions as the mediator in explaining the relationship between subjective well-being and impulsive buying. The indirect support for the hypothesised relationships is also found in other research. For example, Otero-Lopez and Villardefrancos (2013) reported that certain personality traits of neuroticism (anxiety, depression, and impulsiveness), both directly and indirectly through materialism affect excessive buying.

Relative standards theory is one possible explanation for the relationship between subjective well-being, materialism, and impulsive buying. Relative standards theory posits that subjective well-being is a result of comparison of certain standards and actual conditions (Diener \& Ryan, 2009). The social comparison, as noted by those authors, is a strong predictor of personal 
satisfaction with various domains of one's life. Materialists tend to compare themselves with other people important to them and assess themselves accordingly (Sirgy, 1998). They are also more prone to conspicuous and status consumption. A person experiences greater subjective well-being if he feels superior to others, which he chooses as the comparison standard, or when he surpasses earlier version of himself in the past. According to Zhang et al. (2014), because people tend to evaluate their economic conditions not according to whether they have enough to live comfortably, but in comparison to others who have more, even relatively wealthy people can feel poor when they compare themselves with those who are richer. Zhang et al. (2014) argue that such a subjectively perceived relative deprivation increases materialism, because an individual, under the circumstances like this, is more prone to compare his financial situation to that of his peers, while the social comparison, in turn, encourages impulsive consumption with the aim to maintain his social status. Chan and Prendergast (2007) findings also support the assumption that upward social comparison encourages materialistic aspirations. Thus, literature review suggests that the decline of subjective well-being leads to the greater endorsement of materialistic values, which in turn increases the risk of impulsive buying. We propose that materialism function as a mechanism through which subjective well-being is linked with impulsive buying tendency. Based upon the above the following hypothesis is offered:

H4: Subjective well-being has a negative impact on materialism which in turn positively influences impulsive buying.

The conceptual depiction explaining the hypothesised links between subjective well-being, materialism and impulsive buying is shown in figure 1. First, we test the previous literature's findings (respectively we test hypotheses H1, H2, and H3). Finally, we test the H4 hypothesis on the mediating effect of materialism in explaining the subjective well-being indirect effect on impulsive buying. The last hypothesis (H4) summarizes the literature review and is the main contribution of the paper.

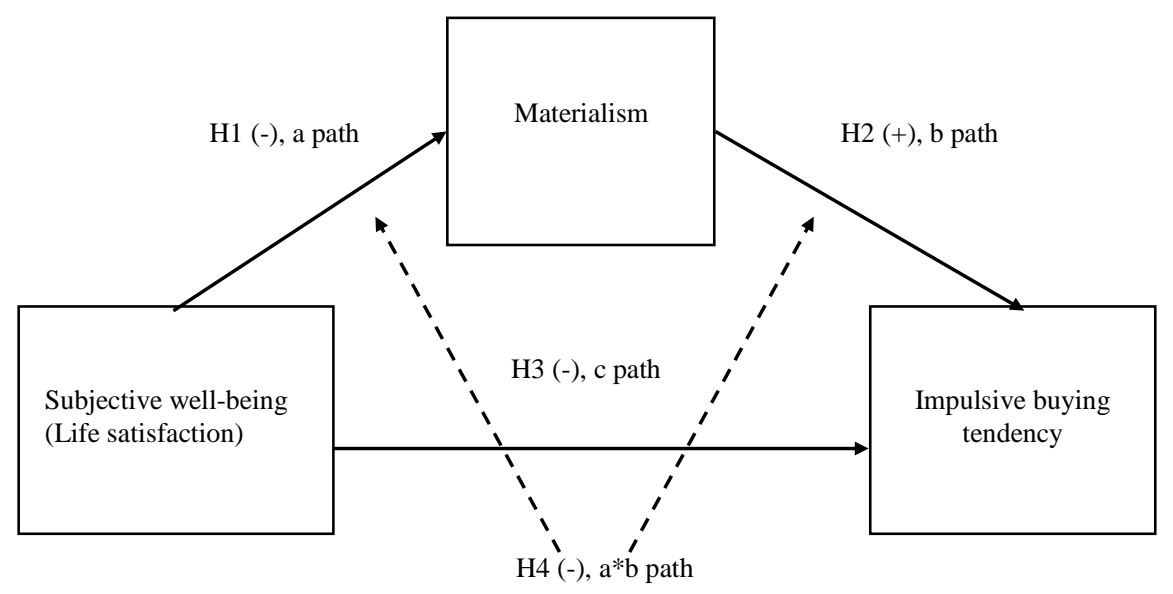

Figure 1. Conceptual Model Explaining the Links between Subjective well-being, Materialism, and Impulsive Buying Tendency

The path $a$ represents the negative effect of subjective well-being on materialism; path $b$ represents the positive effect of materialism on impulsive buying (while controlling for subjective well-being); path $c$ represents the total negative effect of subjective well-being on impulsive buying (absence of mediator). The product of path $a$ and $b$ represents the indirect effect of subjective well-being on impulsive buying, being transmitted through materialism.

\section{Method}

Participants and procedure. The study included a sample of Lithuanian consumers. Participants were recruited through snowballing techniques using the researchers' networks of colleagues and acquaintances. Data collection was conducted online and by distributing printed questionnaires to undergraduate and postgraduate students. In total 313 questionnaires were collected from the 23rd of March 2015 till the 13th of April 2015. The 311 questionnaires were considered properly filled out and valid for further analysis. The sample consisted of 207 females $(66.66 \%)$ and 104 males $(33.4 \%)$. The majority of participants reported that they are still studying at the university or college $(51.8 \%)$. The larger share of participants belonged to the 18 to $24(50.8 \%)$ and 25 to 35 $(25.1 \%)$ age groups. Nearly half of the participants fell into the low-income categories (under 300 EUR and 301-400 EUR). However, $12.2 \%$ of respondents placed themselves in the relatively high-income group (Over 901 EUR).

Measures. Subjective well-being (satisfaction with life). The five statements seven-point Satisfaction With Life Scale (Pavot et al., 1991) was used to measure the perceived global life satisfaction which is considered to be a cognitive aspect of subjective well-being. The Satisfaction With Life Scale in the current study has good internal consistency, with a Cronbach alpha coefficient reported of 0.846 .

Materialism. We employed the widely used Richins and Dawson (1992) 9 item scale (shorter version) that measures the intensity of materialistic value endorsement. 
The Materialism Centrality scale had three seven-point Likert-type items and was intended to measure the extent to which a person believes that buying and owning things are important in their life $(\alpha=0.49)$. The Materialism Happiness scale was composed of three seven-point Likerttype statements assessing the degree to which a person believes that the number and quality of a person's possessions are necessary to achieve happiness in life $(\alpha=0.67)$. Materialism Success seven-point Likert-type subscale consisting of three statements were used to measure the degree to which a person believes that the number and quality of a person's possessions are indicators of success in life (Cronbach's alpha for this sample was acceptable 0.75). Materialism success and centrality subscales' Cronbach's alpha scores were low (0.67 and 0.491 , respectively) suggesting unacceptable internal consistency reliability for these subscales in this sample. Based on Pallant (2007) it is sometimes difficult to get a decent Cronbach alpha value for scales with a small number of items. Therefore for the further analysis, we used the combined version of materialism scale (Cronbach's alpha for this sample was acceptable, $\alpha=0.73$ ). It is in line with Richins (2004) recommendations to use the shorter nine-item version as an acceptable measure of general materialism.

Impulsive buying tendency. Impulsive buying tendency refers to the degree to which an individual is likely to make an impulse purchase of products in general (Jones et al., 2003). To measure this construct we used the twenty-item scale developed by Verplanken and Herabadi (2001). The impulsive buying tendency is treated as a higher order construct including cognitive (10 items) and affective aspects (10 items). Impulsive buying tendency scale (whole) demonstrated good reliability $(\alpha=0.85)$.

\section{Results}

Common Method Bias. Because the same source data were used, the potential for measurement error might be present. To address common method bias, Harman's single factor test was conducted. The result is obtained by running unrotated, a single factor constraint of factor analysis in SPSS statistic. The $26.42 \%$ variance explained by a single factor shows that the common method bias is not a major concern in this study (less than $50 \%$ of the variance stem from the first component) (Mat Roni, 2014).

Hypothesis Testing Results. Table 1 shows correlations, means, standard deviations, and reliabilities. The results shown in Table 1 are partially consistent with the theoretical propositions, as the correlations involving satisfaction with life and materialism (happiness facet and general materialism) were negative and statistically significant $\left(r_{s}=-0.217, p<0.01 ; r_{s}=-0.165, p<0.01\right)$. There was a positive and statistically significant correlation between materialism (success, centrality and general) and impulsive buying tendency (whole), indicating that preoccupation with materialistic values was related to greater impulsive buying tendency $\left(r_{s}=0.168, p<0.01 ; r_{s}=\right.$ $0.16, p<0.01 ; r_{s}=0.174, p<0.01$, respectively). All facets of materialism (success, centrality, happiness and general materialism) were positively and significantly correlated with impulsive buying tendency affective subscale $\left(r_{s}=\right.$
$0.22, p<0.01 ; r_{s}=0.199, p<0.01 ; r_{s}=0.175, p<0.01 ; r_{s}=$ $0.256, p<0.01$, respectively). However, the association between materialism and cognitive dimension of impulsive buying tendency was nonsignificant. Contrary to the predictions, correlations between life satisfaction and all measures of impulsive buying tendency were statistically insignificant.

To test the hypotheses we used PROCESS macro (model 4) for SPSS (Hayes, 2013) with a bias-corrected bootstrapping procedure. PROCESS generates output with the number of regressions whose results are summarized in Table 2. First, we considered the relationship between subjective well-being (life satisfaction) and materialism. As expected, respondents who reported a higher degree of life satisfaction reported a lower preoccupation with materialistic values ( $a$ path, $B=-0.15, S E=0.05, p=0.004,95$ $\%$ LLCI $=-0.25$, ULCI $=-0.05$; where LLCI is the lower bound of the confidence interval and ULCI is the upper bound of confidence interval). The coefficient of $a$ path shows that life satisfaction has a negative impact on materialism, supporting $\mathrm{H} 1$ hypothesis. The results of the regression of impulsive buying tendency predicted from both materialism and life satisfaction show that materialism significantly predicts impulsive buying tendency when controlling for the impact of life satisfaction. The effect of materialism on impulsive buying was significant and positive ( $b$ path, $B=0.16, S E=0.06$, $p=0.004,95 \% \quad \mathrm{LLCI}=0.05, \quad \mathrm{ULCI}=0.28$ ), therefore supporting hypothesis $\mathrm{H} 2$. However, after controlling for materialism, the direct effect of life satisfaction on impulsive buying tendency was eliminated ( $c^{\prime}$ path, $B=-$ $0.03, S E=0.04, p=0.48,95 \% \mathrm{LLCI}=-0.11$, ULCI=0.05). Contrary to prediction (H3 was not supported), there was a nonsignificant total effect (when the mediator is not present in the model) of life satisfaction on impulsive buying tendency ( $c$ path, $B=-0.053, S E=0.04, p=0.2,95 \%$ $\mathrm{LLCI}=-0.13$, ULCI $=0.03$ ), presupposing the suppression (Zhao, Lynch \& Chen, 2010).

Next, we considered whether materialism would mediate the life satisfaction and impulsive buying relationship. To test the proposed underlying process, we used bias-corrected bootstrapping to generate a $95 \%$ confidence interval around the indirect effect of materialism, where mediation occurs if the confidence interval excludes zero (Hayes, 2013). The analysis (10000 bootstrap samples; bias-corrected confidence intervals estimated and reported) revealed a significant indirect effect $(a * b=-0.024, \quad S E=0.012,95 \%$ LLCI $=-0.055$, $\mathrm{ULCI}=-0.006$, these results are generated by PROCESS macros). As predicted, the decrease in life satisfaction increases materialism, which subsequently increases inclination toward impulsive buying. The results of hypothesis testing are shown in Figure 2. 
Correlation Matrix, Descriptive Statistics, and Internal Reliabilities

\begin{tabular}{|c|c|c|c|c|c|c|c|c|}
\hline & 1 & 2 & 3 & 4 & 5 & 6 & 7 & 8 \\
\hline 1. Materialism Success & 1 & & & & & & & \\
\hline 2. Materialism Centrality & $0.436^{* *}$ & 1 & & & & & & \\
\hline 3. Materialism Happiness & $0.340^{* *}$ & $0.317^{* *}$ & 1 & & & & & \\
\hline 4. Materialism (general) & $0.799^{* *}$ & $0.668^{* *}$ & $0.759^{* *}$ & 1 & & & & \\
\hline $\begin{array}{l}\text { 5. Impulsive buying tendency } \\
\text { Cognitive }\end{array}$ & 0.094 & 0.105 & -0.023 & 0.074 & 1 & & & \\
\hline $\begin{array}{l}\text { 6. Impulsive buying tendency } \\
\text { Affective }\end{array}$ & $0.220^{* *}$ & $0.199^{* *}$ & $0.175^{* *}$ & $0.256^{* *}$ & $0.530^{* *}$ & 1 & & \\
\hline $\begin{array}{l}\text { 7. Impulsive buying tendency } \\
\text { (whole) }\end{array}$ & $0.168^{* *}$ & $0.160^{* *}$ & 0.079 & $0.174^{* *}$ & $0.873^{* *}$ & $0.862^{* *}$ & 1 & \\
\hline 8. Life satisfaction & -0.081 & -0.095 & $-0.217^{* *}$ & $-0.165^{* *}$ & -0.045 & -0.049 & -0.061 & 1 \\
\hline Mean & 3.583 & 4.064 & 4.489 & 4.045 & 3.099 & 3.417 & 3.249 & $4.70(23.51)$ \\
\hline SD & 1.283 & 0.743 & 1.304 & 0.855 & 0.868 & 0.926 & 0.785 & $1.08(5.42)$ \\
\hline Cronbach $\alpha$ & 0.670 & 0.491 & 0.750 & 0.730 & 0.810 & 0.770 & 0.854 & 0.846 \\
\hline
\end{tabular}

* Correlation is significant at the 0.05 level (2-tailed). ** Correlation is significant at the 0.01 level (2-tailed). $\mathrm{N}=311$.

$\mathrm{SD}-$ standard deviation. In parenthesis - mean and SD of the total score for Satisfaction with life.

Table 2

Model Coefficients for the Life Satisfaction-Materialism-Impulsive Buying Tendency Relationship Study

\begin{tabular}{|c|c|c|c|c|c|c|c|c|}
\hline \multirow{3}{*}{ Antecedent } & \multirow[b]{3}{*}{ path } & \multicolumn{7}{|c|}{ Consequent } \\
\hline & & \multicolumn{3}{|c|}{ M (Materialism general) } & \multirow[b]{2}{*}{ path } & \multicolumn{3}{|c|}{$Y$ (impulsive buying tendency whole) } \\
\hline & & Coeff. $B$ & $S E$ & $p$ & & Coeff. $B$ & $S E$ & $p$ \\
\hline $\mathrm{X}$ (Life satisfaction) & $a$ & -0.147 & 0.05 & $\begin{array}{l}0.004 * * \\
\text { CI }[-0.25,-0.05]\end{array}$ & $c^{\prime}$ & -0.029 & 0.041 & $\begin{array}{l}0.478 \\
\text { CI [-0.11 } 0.05]\end{array}$ \\
\hline M (Materialism general) & & -------- & ----- & ------ & $b$ & 0.164 & 0.056 & $\begin{array}{l}0.004 * * \\
\text { CI }[0.05,0.28]\end{array}$ \\
\hline Constant & $i_{1}$ & 4.735 & 0.24 & $0.000^{* *}$ & $i_{2}$ & 2.723 & 0.32 & $0.000^{* *}$ \\
\hline & & $F=($ & $\begin{array}{r}R^{2}= \\
09)=8\end{array}$ & $\begin{array}{l}35 \\
4, p=0.004^{* *}\end{array}$ & & & $308)=$ & $p=0.008^{* *}$ \\
\hline
\end{tabular}

** $p<0.01$, Bca $95 \% \mathrm{CI}$ are based on 10000 bootstrap samples.

Path $c$ (total effect of $\mathrm{X}$ on $\mathrm{Y})=c^{\prime}+(a * b)=-0.029+(-0.15 * 0.16)=-0.053$ (LLCI $=-0.13$, ULCI $\left.=0.03\right)$

The indirect effect of $\mathrm{X}$ on $\mathrm{Y}$ (through $\mathrm{M})=a * b=-0.024$ (LLCI $=-0.055$, ULCI $=-0.006$ ).

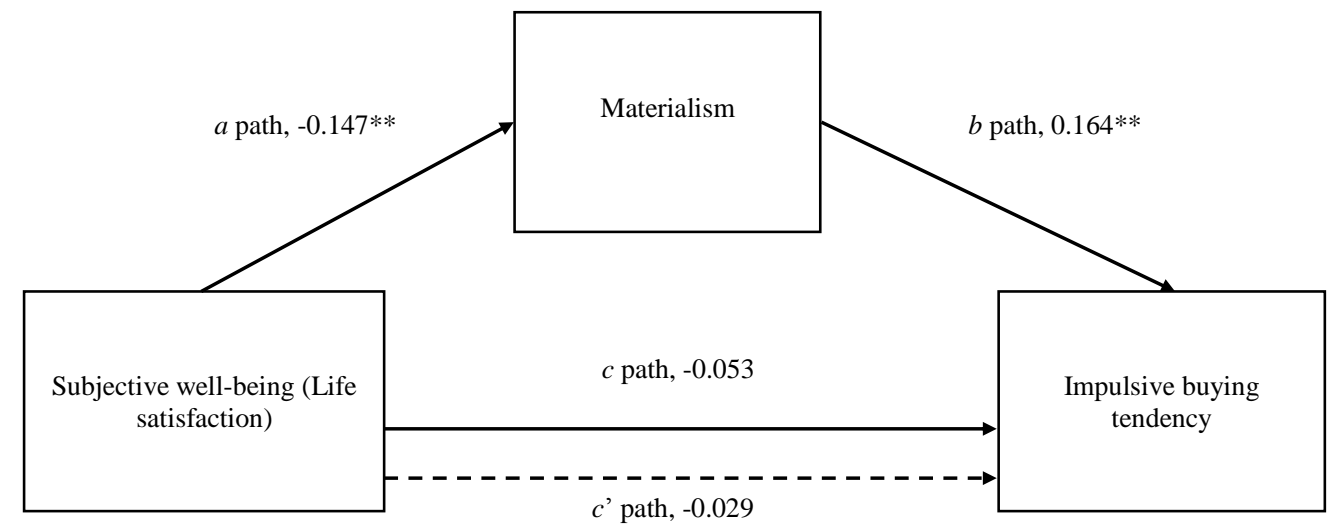

Figure 2. Relationship between subjective well-being, materialism, and impulsive buying tendency

\section{Conclusions}

The main objective of the present study was to examine the interrelationships between subjective well-being, materialism, and impulsive buying tendency. Based on the theorising that materialism functions as coping mechanism of the undesirable psychological state we contend that decline in subjective well-being induces endorsement of materialistic values. Materialism as the result of personal dysfunction is undertaken to compensate personal deficiencies and to cope with negative feelings. In line with the earlier research, our study found that satisfaction with 
life (a cognitive aspect of subjective well-being) was negatively related to materialism. As predicted individuals whose appraisal of their satisfaction with life was worse showed a higher predisposition toward materialism.

Literature review shows that materialistic values, inducing the desire for possession, are found to be positively related to impulsive buying. Based on the notion that materialism exhibits the strong desire for wealth and possession it is suggested that such values direct person to consumption characterized as the strategy helping to repair the mood and identity through material goods. Consistent with expectations, the survey results of our study demonstrated that materialism was a statistically significant predictor of impulsive buying tendency. This finding indicates that the higher the level of materialism, the more likely one is susceptible to the temptation to buy on impulse when faced with an attractive object that can provide a hedonic emotional elevation from the purchase (whether it is the motivation to cope with the incompatibility of identity or with a negative mood).

Based on escape theory the engagement into mood elevating or emotional suffering alleviating buying (respectively impulsive buying) is defined as a response to disappointment and low satisfaction with life. Given that we hypothesised that subjective well-being (respectively satisfaction with life) should have a negative impact on impulsive buying. Unlike previous studies (Silvera at al., 2008; Manolis \& Roberts, 2012; Otero-Lopez et al., 2011) we did not find that decline in satisfaction with life leads to a greater degree of impulsive buying tendency.

The main contribution of this research is the attempt to explain the underlying process linking subjective wellbeing, materialism, and impulsive buying. Based on relative standards theory we contend that the decline of subjective well-being leads to the higher degree of endorsement of materialistic values, which in turn increases the propensity toward impulsive buying. We proposed that materialism functions as a mechanism through which subjective well-being is linked with impulsive buying. As predicted, the relationship between subjective well-being (respectively satisfaction with life) and impulsive buying tendency were mediated by an increase in materialism. Our findings showed that dissatisfaction with life increases materialism, which subsequently increases inclination toward impulsive buying. Thus, it appears that satisfaction with life and impulsive buying is only indirectly related through the increase in materialism. The results of this study contribute to the understanding of the phenomenon of materialism by exploring the underlying process by which the subjective well-being impacts impulsive buying tendency.

Limitation of this study is the correlational design, which does not allow claiming causal relationships. Our study is also limited by the use of the predominantly university students as a source of information, therefore preventing from the generalising of findings to other groups of the population. In our study, we treated impulsive buying to be a less pronounced manifestation of compulsive buying and used these concepts interchangeably. However, we tested the hypothesis using impulsive buying tendency scale. Therefore, the current study applies to the impulsive buyers only. Some authors classify impulsive and compulsive buying as qualitatively different concepts. Future studies with the inclusion of separate measures of impulsive and compulsive buying will be useful to determine whether the associations detected in present study persists while applying separate operationalisations of impulsive and compulsive buying.

\section{References}

Badgaiyan, A. J., \& Verma, A. (2014). Intrinsic factors affecting impulsive buying behaviour-Evidence from India. Journal of Retailing and consumer services, 21(4), 537-549. https://doi.org/10.1016/j.jretconser.2014.04.003

Bauer, M. A., Wilkie, J. E., Kim, J. K., \& Bodenhausen, G. V. (2012). Cuing consumerism situational materialism undermines personal and social well-being. Psychological Science, 23(5), 517-523. https://doi.org/10.1177/ 0956797611429579

Beatty, S. E., \& Ferrell, M. E. (1998). Impulse buying: Modeling its precursors. Journal of retailing, 74(2), $169-191$. https://doi.org/10.1016/S0022-4359(99)80092-X

Belk, R. W. (1985). Materialism: Trait aspects of living in the material world. Journal of Consumer research, 265-280. https://doi.org/10.1086/208515

Boujbel, L., \& d'Astous, A. (2015). Exploring the feelings and thoughts that accompany the experience of consumption desires. Psychology \& Marketing, 32(2), 219-231. https://doi.org/10.1002/mar.20774

Brickman, P., \& Campbell, D. T. (1971). Hedonic relativism and planning the good science. In. MH Appley (Ed.), Adaptation level theory: A symposium (pp. 287-302).

Burroughs, J. E., \& Rindfleisch, A. (2002). Materialism and well-being: A conflicting values perspective. Journal of Consumer research, 29(3), 348-370. https://doi.org/10.1086/344429

Burroughs, J. E., \& Rindfleisch, A. (2012). What welfare? On the definition and domain of transformative consumer research and the foundational role of materialism. Transformative consumer research for personal and collective well-being, 249-266.

Burroughs, J. E., Chaplin, L. N., Pandelaere, M., Norton, M. I., Ordabayeva, N., Gunz, A., \& Dinauer, L. (2013). Using Motivation Theory to Develop a Transformative Consumer Research Agenda for Reducing Materialism in Society. Journal of Public Policy \& Marketing, 32(1), 18-31. https://doi.org/10.1509/jppm.10.046 
Beata Seinauskiene, Jurate Mascinskiene, Indre Petrike, Ausra Rutelione. Materialism as the Mediator of the Association...

Clark, M., \& Calleja, K. (2008). Shopping addiction: A preliminary investigation among Maltese university students. Addiction Research \& Theory, 16(6), 633-649. https://doi.org/10.1080/16066350801890050

Chan, K., \& Prendergast, G. (2007). Materialism and social comparison among adolescents. Social Behavior and Personality: an international journal, 35(2), 213-228. https://doi.org/10.2224/sbp.2007.35.2.213

Chancellor, J., \& Lyubomirsky, S. (2011). Happiness and thrift: When (spending) less is (hedonically) more. Journal of Consumer Psychology, 21(2), 131-138. https://doi.org/10.1016/j.jcps.2011.02.004

d'Astous, A. (1990). An inquiry into the compulsive side of "normal" consumers. Journal of Consumer Policy, 13(1), 1531. https://doi.org/10.1007/BF00411867

Darrat, A. A., Darrat, M. A., \& Amyx, D. (2016). How impulse buying influences compulsive buying: The central role of consumer anxiety and escapism. Journal of Retailing and Consumer Services, 31, $103-108$. https://doi.org/10.1016/ j.jretconser.2016.03.009

Diener, E. (1984). Subjective well-being. Psychological Bulletin (85), 542-575. https://doi.org/10.1037/00332909.95.3.542

Diener, E. (2000). Subjective well-being: The science of happiness and a proposal for a national index. American psychologist, 55(1), 34. https://doi.org/10.1037/0003-066X.55.1.34

Diener, E., \& Chan, M. Y. (2011). Happy people live longer: Subjective well-being contributes to health and longevity. Applied Psychology: Health and Well-Being, 3(1), 1-43. https://doi.org/10.1111/j.1758-0854.2010.01045.x

Diener, E., \& Ryan, K. (2009). Subjective well-being: a general overview. South African Journal of Psychology, 39(4), 391-406. https://doi.org/10.1177/008124630903900402

Dittmar, H. (2005). A new look at" compulsive buying": Self-discrepancies and materialistic values as predictors of compulsive buying tendency. Journal of Social and Clinical Psychology, 24(6), 832. https://doi.org/10. 1521/jscp.2005.24.6.832

Dittmar, H., \& Bond, R. (2010). I want it and I want it now: Using a temporal discounting paradigm to examine predictors of consumer impulsivity. British Journal of Psychology, 101(4), 751-776. https://doi.org/10. 1348/000712609X484658

Dittmar, H., Bond, R., Hurst, M., \& Kasser, T. (2014). The relationship between materialism and personal well-being: A meta-analysis. Journal of personality and social psychology, 107(5), 879. https://doi.org/10.1037/a0037409

Faber, R. J. (2006). A theoretical account for compulsive buying: An application of escape theory. Advances in Consumer Research, 33(1), 131-133.

Faber, R. J., \& O'Guinn, T. C. (2008). Compulsive buying: Review and reflection. Handbook of consumer psychology, 1039-1056.

Faber, R. J., \& Christenson, G. A. (1996). In the mood to buy: Differences in the mood states experienced by compulsive buyers and other consumers. Psychology \& Marketing, 13(8), 803-819. https://doi.org/10.1002/(SICI)15206793(199612)13:8<803::AID-MAR6>3.0.CO;2-J

Flight, R. L., Rountree, M. M., \& Beatty, S. E. (2012). Feeling the urge: Affect in impulsive and compulsive buying. Journal of Marketing Theory and Practice, 20(4), 453-466. https://doi.org/10.2753/MTP1069-6679200407

Garðarsdottir, R. B., \& Dittmar, H. (2012). The relationship of materialism to debt and financial well-being: The case of Iceland's perceived prosperity. Journal of Economic Psychology, 33(3), 471-481. https://doi.org/10. 1016/j.joep.2011.12.008

Good, J. (2007). Shop'til we drop? Television, materialism and attitudes about the natural environment. Mass Communication \& Society, 10(3), 365-383. https://doi.org/10.1080/15205430701407165

Harnish, R. J., \& Bridges, K. R. (2015). Compulsive buying: the role of irrational beliefs, materialism, and narcissism. Journal of Rational-Emotive \& Cognitive-Behavior Therapy, 33(1), 1-16. https://doi.org/10.1007/s10942-0140197-0

Hayes, A. F. (2013). Introduction to mediation, moderation, and conditional process analysis: A regression-based approach. Guilford Press.

Herabadi, A. G., Verplanken, B., \& Van Knippenberg, A. (2009). Consumption experience of impulse buying in Indonesia: Emotional arousal and hedonistic considerations. Asian Journal of Social Psychology, 12(1), 20-31. https://doi.org/10.1111/j.1467-839X.2008.01266.X

Jones, M. A., Reynolds, K. E., Weun, S., \& Beatty, S. E. (2003). The product-specific nature of impulse buying tendency. Journal of business research, 56(7), 505-511. https://doi.org/10.1016/S0148-2963(01)00250-8

Kasser, T., \& Ryan, R. M. (1993). A dark side of the American dream: correlates of financial success as a central life aspiration. Journal of personality and social psychology, 65(2), 410. https://doi.org/10.1037/0022-3514.65.2.410 
Kasser, T., \& Sheldon, K. M. (2000). Of wealth and death: Materialism, mortality salience, and consumption behavior. Psychological science, 11(4), 348-351. https://doi.org/10.1111/1467-9280.00269

Kasser, T. (2002). The high price of materialism. MIT press.

Kasser, T., \& Ahuvia, A. (2002). Materialistic values and well-being in business students. European Journal of Social Psychology, 32(1), 137-146. https://doi.org/10.1002/ejsp.85

Kasser, T., Ryan, R. M., Couchman, C. E., \& Sheldon, K. M. (2004). Materialistic values: Their causes and consequences. Psychology and consumer culture: The struggle for a good life in a materialistic world, 11-28. https://doi.org/10.1037/10658-002

Kasser, T., Rosenblum, K. L., Sameroff, A. J., Deci, E. L., Niemiec, C. P., Ryan, R. M., ... \& Hawks, S. (2014). Changes in materialism, changes in psychological well-being: Evidence from three longitudinal studies and an intervention experiment. Motivation and Emotion, 38(1), 1-22. https://doi.org/10.1007/s11031-013-9371-4

Kwak, H., Zinkhan, G. M., DeLorme, D. E., \& Larsen, T. (2006). Revisiting normative influences on impulsive buying behavior and an extension to compulsive buying behavior: A case from South Korea. Journal of International Consumer Marketing, 18(3), 57-80. https://doi.org/10.1300/J046v18n03_04

Lastovicka, J. L., \& Sirianni, N. J. (2011). Truly, madly, deeply: Consumers in the throes of material possession love. Journal of Consumer Research, 38(2), 323-342. https://doi.org/10.1086/658338

Lemrova, S., Reiterova, E., Fatenova, R., Lemr, K., \& Tang, T. L. P. (2014). Money is power: Monetary intelligencelove of money and temptation of materialism among Czech University students. Journal of Business Ethics, 125(2), 329-348. https://doi.org/10.1007/s10551-013-1915-8

Luhmann, M., Hofmann, W., Eid, M., \& Lucas, R. E. (2012). Subjective well-being and adaptation to life events: a metaanalysis. Journal of personality and social psychology, 102(3), 592. https://doi.org/10.1037/a0025948

Luomala, H. T. (2002). An empirical analysis of the practices and therapeutic power of mood-alleviative consumption in Finland. Psychology \& Marketing, 19(10), 813-836. https://doi.org/10.1002/mar.10039

Manolis, C., \& Roberts, J. A. (2012). Subjective well-being among adolescent consumers: the effects of materialism, compulsive buying, and time affluence. Applied Research in Quality of Life, 7(2), 117-135. https://doi.org/10. 1007/s11482-011-9155-5

Mat Roni, S. (2014). Introduction to SPSS, School of Business, Edith Cowan University, Australia. Retrieved [2016.10.14] from www.researchgate.net/publication/262151892_Introduction_to_SPSS.

Muller, A., Mitchell, J. E., Peterson, L. A., Faber, R. J., Steffen, K. J., Crosby, R. D., \& Claes, L. (2011). Depression, materialism, and excessive Internet use in relation to compulsive buying. Comprehensive Psychiatry, 52(4), 420424. https://doi.org/10.1016/j. comppsych.2010.09.001

Müller, A., Claes, L., Georgiadou, E., Möllenkamp, M., Voth, E. M., Faber, R. J., \& de Zwaan, M. (2014). Is compulsive buying related to materialism, depression or temperament? Findings from a sample of treatment-seeking patients with CB. Psychiatry research, 216(1), 103-107. https://doi.org/10.1016/j.psychres.2014.01.012

O'Guinn, T. C., \& Faber, R. J. (1989). Compulsive buying: A phenomenological exploration. Journal of consumer research, 147-157. https://doi.org/10.1086/209204

Otero-Lopez, J. M., Pol, E. V., Bolano, C. C., \& Marino, M. J. S. (2011). Materialism, life-satisfaction and addictive buying: Examining the causal relationships. Personality and Individual Differences, 50(6), $772-776$. https://doi.org/10.1016/j. paid.2010.12.027

Otero-Lopez, J. M., \& Villardefrancos, E. (2013). Five-Factor Model personality traits, materialism, and excessive buying: A mediational analysis. Personality and Individual Differences, 54(6), 767-772. https://doi.org/10. 1016/j.paid.2012.12.013

Pallant, J. (2007). SPSS Survival Manual: A step-by-step guide to data analysis using SPSS for Windows (Version 10).

Pavot, W., Diener, E. D., Colvin, C. R., \& Sandvik, E. (1991). Further validation of the satisfaction with life scale: Evidence for the cross-method convergence of well-being measures. Journal of personality assessment, 57(1), 149-161. https://doi.org/10.1207/s15327752jpa5701_17

Podoshen, J. S., \& Andrzejewski, S. A. (2012). An examination of the relationships between materialism, conspicuous consumption, impulse buying, and brand loyalty. Journal of Marketing Theory and Practice, 20(3), 319-334. https://doi.org/10.2753/ MTP1069-6679200306

Podoshen, J. S., Andrzejewski, S. A., \& Hunt, J. M. (2014). Materialism, Conspicuous Consumption, and American HipHop Subculture. Journal of International Consumer Marketing, 26(4), 271-283. https://doi.org/10.1080/ 08961530.2014.900469

Punj, G. (2011). Impulse buying and variety seeking: Similarities and differences. Journal of Business Research, 64(7), 745-748. https://doi.org/10.1016/j.jbusres.2010.07.007 
Beata Seinauskiene, Jurate Mascinskiene, Indre Petrike, Ausra Rutelione. Materialism as the Mediator of the Association...

Reeves, R. A., Baker, G. A., \& Truluck, C. S. (2012). Celebrity worship, materialism, compulsive buying, and the empty self. Psychology \& Marketing, 29(9), 674-679. https://doi.org/10.1002/mar.20553

Richins, M. L. (1994). Valuing things: The public and private meanings of possessions. Journal of consumer research, 21(3), 504-521. https://doi.org/10.1086/209414

Richins, M. L. (2004). The material values scale: Measurement properties and development of a short form. Journal of consumer research, 31(1), 209-219. https://doi.org/10.1086/383436

Richins, M. L. (2011). Materialism, transformation expectations, and spending: Implications for credit use. Journal of Public Policy \& Marketing, 30(2), 141-156. https://doi.org/10.1509/jppm.30.2.141

Richins, M. L. (2013). When wanting is better than having: Materialism, transformation expectations, and productevoked emotions in the purchase process. Journal of Consumer Research, 40(1), 1-18. https://doi.org/10. $1086 / 669256$

Richins, M. L., \& Dawson, S. (1992). A consumer values orientation for materialism and its measurement: Scale development and validation. Journal of consumer research, 19(3), 303. https://doi.org/10.1086/209304

Ridgway, N. M., Kukar-Kinney, M., \& Monroe, K. B. (2008). An expanded conceptualization and a new measure of compulsive buying. Journal of Consumer Research, 35(4), 622-639. https://doi.org/10.1086/591108

Roberts, J. A., \& Clement, A. (2007). Materialism and satisfaction with over-all quality of life and eight life domains. Social Indicators Research, 82(1), 79-92. https://doi.org/10.1007/s11205-006-9015-0

Roberts, J. A., Manolis, C., \& Tanner Jr, J. F. (2008). Interpersonal influence and adolescent materialism and compulsi ve buying. Social Influence, 3(2), 114-131. https://doi.org/10.1080/15534510802185687

Roberts, J. A., \& Pirog III, S. F. (2012). A preliminary investigation of materialism and impulsiveness as predictors of technological addictions among young adults. Journal of Behavioral Addictions, 2(1), 56-62. https://doi.org/10. 1556/JBA.1.2012.011

Roberts, J. A., Yaya, P., Honore, L., \& Gwin, C. (2015). Yielding to Temptation in Buying: Is It Simply a Matter of SelfControl?. Atlantic Marketing Journal, 4(2), 5.

Rodriguez-Villarino, R., Gonzalez-Lorenzo, M., Fernandez-Gonzalez, A., Lameiras-Fernandez, M., \& Foltz, M. L. (2006). Individual factors associated with buying addiction: An empirical study. Addiction Research \& Theory, 14(5), 511-525. https://doi.org/10.1080/16066350500527979

Rook, D. W., \& Hoch, S. J. (1985). Consuming impulses. NA-Advances in Consumer Research Volume 12.

Rook, D. W. (1987). The buying impulse. Journal of consumer research, 14(2), 189-199. https://doi.org/10.1086/209105

Rook, D. W., \& Gardner, M. P. (1993). In the mood: Impulse buying's affective antecedents. Research in consumer behavior, 6(7), 1-28.

Rose, P. (2007). Mediators of the association between narcissism and compulsive buying: the roles of materialism and impulse control. Psychology of addictive behaviors, 21(4), 576. https://doi.org/10.1037/0893-164X.21.4.576

Ruvio, A., Somer, E., \& Rindfleisch, A. (2014). When bad gets worse: the amplifying effect of materialism on traumatic stress and maladaptive consumption. Journal of the Academy of Marketing Science, 42(1), 90-101. https://doi.org/10.1007/ s11747-013-0345-6

Scott, K., Martin, D. M., \& Schouten, J. W. (2014). Marketing and the New Materialism. Journal of Macromarketing, https://doi.org/10.1177/0276146714532471

Segev, S., Shoham, A., \& Gavish, Y. (2015). A closer look into the materialism construct: the antecedents and consequences of materialism and its three facets. Journal of Consumer Marketing, 32(2), 85-98. https://doi.org/10.1108/JCM-07-2014-1082

Sharma, P., Sivakumaran, B., \& Marshall, R. (2010). Impulse buying and variety seeking: A trait-correlates perspective. Journal of Business Research, 63(3), 276-283. https://doi.org/10.1016/j.jbusres.2009.03.013

Silvera, D. H., Lavack, A. M., \& Kropp, F. (2008). Impulse buying: The role of affect, social influence, and subjective wellbeing. Journal of Consumer Marketing, 25(1), 23-33. https://doi.org/10.1108/07363760810845381

Sirgy, M. J. (1998). Materialism and quality of life. Social indicators research, 43(3), 227-260. https://doi.org/10.1023/A :1006820429653

Shrum, L. J., Lowrey, T. M., Pandelaere, M., Ruvio, A. A., Gentina, E., Furchheim, P., \& Nairn, A. (2014). Materialism: the good, the bad, and the ugly. Journal of Marketing Management, 30(17-18), 1858-1881. https://doi.org/10. 1080/0267257X.2014.959985

Sneath, J. Z., Lacey, R., \& Kennett-Hensel, P. A. (2009). Coping with a natural disaster: Losses, emotions, and impulsive and compulsive buying. Marketing Letters, 20(1), 45-60. https://doi.org/10.1007/s11002-008-9049-y 
Sun, T., \& Wu, G. (2011). Trait predictors of online impulsive buying tendency: A hierarchical approach. Journal of Marketing Theory and Practice, 19(3), 337-346. https://doi.org/10.2753/MTP1069-6679190307

Thompson, E. R., \& Prendergast, G. P. (2015). The influence of trait affect and the five-factor personality model on impulse buying. Personality and Individual Differences, 76, 216-221. https://doi.org/10.1016/j.paid.2014.12.025

Tifferet, S., \& Herstein, R. (2012). Gender differences in brand commitment, impulse buying, and hedonic consumption. Journal of Product \& Brand Management, 21(3), 176-182. https://doi.org/10.1108/10610421211228793

Tsang, J. A., Carpenter, T. P., Roberts, J. A., Frisch, M. B., \& Carlisle, R. D. (2014). Why are materialists less happy? The role of gratitude and need satisfaction in the relationship between materialism and life satisfaction. Personality and Individual Differences, 64, 62-66. https://doi.org/10.1016/j.paid.2014.02.009

Unanue, W., Dittmar, H., Vignoles, V. L., \& Vansteenkiste, M. (2014). Materialism and Well-being in the UK and Chile: Basic Need Satisfaction and Basic Need Frustration as Underlying Psychological Processes. European Journal of Personality, 28(6), 569-585. https://doi.org/10.1002/per.1954

Verplanken, B., \& Herabadi, A. (2001). Individual differences in impulse buying tendency: Feeling and no thinking. European Journal of personality, 15(S1), S71-S83. https://doi.org/10.1002/per.423

Verplanken, B., Herabadi, A. G., Perry, J. A., \& Silvera, D. H. (2005). Consumer style and health: The role of impulsive buying in unhealthy eating. Psychology \& Health, 20(4), 429-441. https://doi.org/10.1080/088 70440412331337084

Verplanken, B., \& Sato, A. (2011). The psychology of impulse buying: An integrative self-regulation approach. Journal of Consumer Policy, 34(2), 197-210. https://doi.org/10.1007/s10603-011-9158-5

Xiao, S. H., \& Nicholson, M. (2011). Mapping impulse buying: a behaviour analysis framework for services marketing and consumer research. The Service Industries Journal, 31(15), 2515-2528.

Xiao, S. H., \& Nicholson, M. (2013). A multidisciplinary cognitive behavioural framework of impulse buying: a systematic review of the literature. International Journal of Management Reviews, 15(3), 333-356.

Yurchisin, J., \& Johnson, K. K. (2004). Compulsive buying behavior and its relationship to perceived social status associated with buying, materialism, self-esteem, and apparel-product involvement. Family and Consumer Sciences Research Journal, 32(3), 291-314.

Zhang, Y., \& Shrum, L. J. (2009). The influence of self-construal on impulsive consumption. Journal of Consumer Research, $35(5), 838-850$.

Zhang, J. W., Howell, R. T., \& Howell, C. J. (2014). Living in wealthy neighborhoods increases material desires and maladaptive consumption. Journal of Consumer Culture, 1469540514521085.

The article has been reviewed.

Received in December, 2015; accepted in November, 2016 